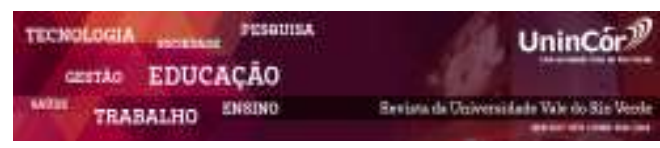

Revista da Universidade Vale do Rio Verde ISSN: 1517-0276 / EISSN: 2236-5362 Vol. 16 | n. 1 | Ano 2018

Wesley Barros da Silva Passos Universidade Estadual do Piauí wesleycopiador@gmail.com

Valdiléia Teixeira Uchôa

Universidade Estadual do Piauí vtuquimica@yahoo.com.br

\section{UMA REVISAO BIBLIOGRÁFICA SOBRE O GOJI BERRY COMO ALIMENTO FUNCIONAL}

\section{RESUMO}

O presente estudo teve como finalidade realizar uma ampla revisão bibliográfica sobre a Goji berry, (Lycium barbarum L.), originária da região da Ásia, suas bagas possuem variadas atividades biológicas, devido à presença de seus compostos funcionais. Para a revisão utilizou-se associação entre os descritores "Goji berry", "Lycium barbarum", "atividade terapêutica" e "alimento funcional" em artigos nacionais e internacionais obtidos das bases de dados Scielo, Scopus, Web of Science e Google acadêmico. Foram encontrados 88 artigos e eleitos 40, para alcançar o objetivo deste estudo. Observou-se que as bagas G. berry, possuem polissacarídeos responsáveis pelas diversas propriedades funcionais, rica em vitamina $\mathrm{C}$, nutriente que melhora o sistema imunológico, o humor, evita problemas oftalmológicos, derrames e ajuda a emagrecer. Suas bagas é a maior fonte conhecida de carotenoides e por isso contribuir para evitar problemas de visão e pode proporcionar foto proteção adicional em pessoas mais suscetíveis aos raios ultravioletas. Possui uma alta ação antioxidante e antiinflamatória, equilibra os níveis do colesterol protegendo o coração e o cérebro, ajuda a diminuir as celulites, previne o diabetes e o câncer. Devido ao grande interesse pelos efeitos causados pelos compostos presentes no Goji berry, vários trabalhos vêm sendo desenvolvidos com intuito de compreender melhor as atividades biológicas apresentadas por seus compostos funcionais.

Palavras-chave: Goji berry. Alimento Funcional. Antioxidante.

\section{A BIBLIOGRAPHIC REVIEW ON GOJI BERRY AS A FUNCTIONAL FOOD}


cancer. Due to the great interest in the effects caused by the compounds present in Goji Berry, several studies have been developed in order to better understand the biological activities presented by their functional compounds.

Keywords: Goji Berry. Functional Food. Antioxidant.

Recebido em: 05/02/2017 - Aprovado em: 10/02/2018 - Disponibilizado em: 15/07/2018

\section{INTRODUÇÂO}

A Lycium barbarum L. (Goji berry), é uma planta da família Solanácea encontrada na China e regiões do Himalaia, posicionada há milênios no topo da tabela das 8000 ervas e alimentos curativos chineses, sendo considerado um medicamento fitoterápico muito utilizado pelo seu potencial antioxidante e revitalizante (MARTINS; MAGALHÃES; SCHILICHTING, 2014). Pode ser consumidas na forma de frutas frescas, desidratadas e em bebidas como licor (AMAGASE, 2011).

Esta planta é um arbusto com até três metros de altura, folhas lanceoladas e ovais. Os frutos são retangulares, de coloração tendendo do laranja ao vermelho escuro. As bagas medem até $2 \mathrm{~cm}$ e possuem um sabor doce (POTTERAT, 2010). Secas a temperatura moderada até o enrugamento da pele e em seguida, exposta à luz solar até a pele torna-se dura, mas o interior permanece macio e estão prontos para o consumo (SALGADO, 2011).

$\mathrm{Na}$ planta existem compostos que agem como antioxidantes, esses são: zeaxantina, luteína, vitaminas $\mathrm{A}, \mathrm{C}, \mathrm{E}, \mathrm{B}_{2}$, betacaroteno, licopeno e taurina, quando esses antioxidantes são aderidos à alimentação evidenciam vários benefícios à saúde, tais como: proteção solar da pele, anti-stress, combate à celulite, emagrecimento, melhoram a visão, antihipertensivo, anti-inflamatórias e no tratamento para infertilidade masculina (CAVAZIM, 2014).

Estudos recentes indicam que o extrato do dos frutos do G. berry possuem uma gama de atividades biológicas. Essas contribuições foram comprovadas e associadas em virtude de seu alto valor nutracêutico. A fruta é rica em polissacarídeos glicoconjugados solúveis em água, ao qual é atribuída a maior parte dos efeitos biológicos do fruto e, em adição a fração solúvel, níveis elevados de vitaminas do complexo B, ácido ascórbico, carotenoides, além de numerosos compostos orgânicos, polifenólicos e fitosteróis (APPOLONI, 2015).

Segundo Silva e Degáspari (2014), estudos realizados com uma bebida à base do suco da fruta do G. berry, apontaram para uma possível diminuição da circunferência abdominal em indivíduos que consumiram diariamente. Esta planta protegem o sistema nervoso central, diminui o risco de glaucoma, antitumoral, previne várias doenças crônicas como hipercolesterolemia, diabetes e hepatite. Reduz a fadiga, aumenta resistência física e é um forte aliado na prevenção do envelhecimento (MARTINS; MAGALHÃES; SCHILICHTING, 2014).

Cuidados devem ser tomados com a ingestão desta fruta, pois pode desencadear 
processo alérgico em pacientes que já tenham sido sensibilizados ao tomate, além de apresentar alguma interação com medicamentos antiplaquetários, diminuindo sua eficácia (SILVA; DESGÁPARI, 2014). A presente revisão de literatura objetivou em relatar de forma ampla e aprofundada os benefícios e as atividades terapêuticas do G. berry.

\section{METODOLOGIA}

A pesquisa desenvolvida apresenta caráter qualitativo, de natureza exploratória, realizada através de uma revisão literária com o intuito de obter uma análise crítica e ampla das publicações correntes em uma determinada área do conhecimento. O método de averiguação fundamentado nesta revisão integrativa buscou manter os padrões de rigor, clareza e respostas dos estudos primários.

Foi realizada uma revisão bibliográfica com artigos nacionais e internacionais obtidos das bases de dados Scielo, Scopus, Web of Science e Google acadêmico, utilizando associação entre os descritores "Goji berry", "Lycium barbarum", "atividade terapêutica" e "alimento funcional", com o intuito de realizar uma análise crítica sobre as atividades terapêuticas do G. berry. Foram encontrados 88 artigos e eleitos 40 artigos científicos após os critérios de inclusão e exclusão, para obter uma maior fonte de conhecimento e respostas dos estudos primários.

Quanto ao período dos artigos utilizados nesta revisão, foram entre os anos de 2009 e 2017. Para fundamentar esses artigos alguns critérios de inclusão e exclusão foram feitos. Para inclusão, foram utilizados apenas artigos científicos que estão voltados especificamente para o estudo da G. Berry, artigos publicados nos últimos dez anos e artigos em português, inglês e espanhol, foram utilizados aproximadamente 40 artigos. Foram excluídos os artigos encontrados em sites que não tivessem uma confiabilidade e credibilidade e não foram utilizados bases de dados que não fossem artigos científicos;

Este estudo foi fundamentado da seguinte forma: primeiramente foi feito um levantamento no nível de conhecimento gerais sobre o G. berry, depois realizado um estudo sobre suas propriedades terapêuticas e por fim os avanços da medicina na utilização das bagas do G. berry

\section{RESULTADOS E DISCUSSÃO}

Analisando os artigos encontrados para este estudo, observou-se que as principais pesquisas sobre o G. berry, relata sobre suas propriedades terapêuticas destacando suas atividades farmacológicas e como alimento funcional. Como grande parte das pesquisas desenvolvidas em países do exterior (83\%), e pesquisas realizadas no Brasil (17\%), apesar do grande contingente de publicações em nível mundial, o Brasil vem desenvolvendo pesquisas importantes para o avanço do conhecimento das propriedades terapêuticas da $L$. barbarum, utilizadas pela população.

Nesta pesquisa bibliográfica, os países que merecem destaque por pesquisarem sobre os efeitos benéficos do G. berry empregados na 
medicina, como alimento funcional e estudos dos seus compostos biotivos são: Suíça e Itália (27\%), Espanha, Estados Unidos e China (30\%), Brasil (17\%), Romênia e Portugal (13\%), Turquia, Eslovênia, Austrália, Bulgária (13\%).

Para a construção da Tabela 1, foram utilizados 29 artigos publicados em 24 revistas, onde somente um artigo de cada revista foi usado, com exceção da Uningá Review, Food Chemistry, Agric. Chem Alimentos, Journal of Food Science e Carbohydrate and Polymers que tiveram dois artigos utilizados cada uma. O que mostra uma variedade de publicações em revistas internacionais com interesse científico no $G$. berry.

A maioria dos artigos utilizados para a construção da Tabela 1 enfatizavam, sobre os estudos que determinam compostos isolados, alimento funcional, atividade antioxidante, toxidade e reações adversas, atividades farmacológicas e fitoterápicas do G. berry.

Portanto, a Tabela 1, apresenta artigos relacionados ao uso do G. berry e suas principais propriedades funcionais e terapêuticas. Devido a seu elevado valor nutricional contendo a presença de compostos antioxidantes, carboidratos e proteínas. O interesse nas bagas de G. berry, teve um aumento significativo nos últimos anos e está se tornando uma opção para os indivíduos que buscam benefícios a saúde, principalmente os praticantes do estilo de vida saudável (BALLARIN el al., 2011).

O Gráfico 1 foi desenvolvido com base nas publicações presentes na Tabela 1, apontando que estudos do G. berry vem se desenvolvendo constantemente em pesquisas voltadas as atividades terapêuticas desta planta. Portanto o Gráfico 1, apresenta as diversas aplicações das bagas do G. berry. Comprovando que o $G$. berry possui várias atividades farmacológicas e dentre elas podemos destacar a atividade antioxidante.

O Gráfico 2, mostra que existe grande interesse na comunidade cientifica em pesquisas voltadas ao G. berry na atualidade, com boas perspectivas em estudos para o futuro. Observamos que nos anos de 2014 a 2015 apresentaram o maior número de publicações sobre o assunto, no entanto o nível de publicações em 2016 vem crescendo.

Esta planta também melhora na acuidade visual, fato este que pôde ser evidenciado em patologias que afetam a visão, principalmente em pacientes onde este sintoma é muito importante e recorrente (CAVAZIN e FREITAS, 2014).

Tabela 1 - Levantamento bibliográfico sobre a utilização do Goji Berry como alimento funcional.

\begin{tabular}{|l|l|l|l|l|l|}
\hline $\begin{array}{l}\text { Autores/ } \\
\text { Ano }\end{array}$ & Local & Objetivo do estudo & Revista & $\begin{array}{l}\text { Tipo de } \\
\text { estudo }\end{array}$ & Aplicação \\
\hline $\begin{array}{l}\text { Adiletta } \\
\text { et. al, } \\
2015\end{array}$ & $\begin{array}{l}\text { Roma, } \\
\text { Itália }\end{array}$ & $\begin{array}{l}\text { Estudar o efeito do pré-tratam } \\
\text { ento abrasi- } \\
\text { vo sobre goji, após o processo }\end{array}$ & $\begin{array}{l}\text { Chemical } \\
\text { Engineerin }\end{array}$ & $\begin{array}{l}\text { Estudo } \\
\text { experimental }\end{array}$ & $\begin{array}{l}\text { Processo de } \\
\text { secagem das } \\
\text { bagas de } G .\end{array}$ \\
\hline
\end{tabular}




\begin{tabular}{|c|c|c|c|c|c|}
\hline & & $\begin{array}{l}\text { de secagem com ar quente a } 6 \\
0^{\circ} \mathrm{C} \text {. }\end{array}$ & & & berry \\
\hline $\begin{array}{l}\text { Cardozo } \\
\text { e Mafra, } \\
2015\end{array}$ & $\begin{array}{l}\text { Niterói, } \\
\text { RJ - Brasil }\end{array}$ & $\begin{array}{l}\text { Mostrar a importância do } G \text {. } \\
\text { berry juntos com outros } \\
\text { alimentos impostos na dieta } \\
\text { pode levar a benefícios para o } \\
\text { Sistema Cardiovascular. }\end{array}$ & $\begin{array}{l}\text { Internacional Journal } \\
\text { of Cardiovascular } \\
\text { Sciences }\end{array}$ & $\begin{array}{l}\text { Revisão } \\
\text { Bibliográfica }\end{array}$ & $\begin{array}{l}\text { Alimento } \\
\text { funcional }\end{array}$ \\
\hline $\begin{array}{l}\text { Carvalho } \\
\text { P. et. al, } \\
2016\end{array}$ & $\begin{array}{l}\text { Porto, } \\
\text { Portugal }\end{array}$ & $\begin{array}{l}\text { Avaliar o efeito da extração } \\
\text { assistida por micro-ondas na } \\
\text { composição e de bioatividade } \\
\text { de extratos goji ( } L \text {. } \\
\text { barbarum). }\end{array}$ & $\begin{array}{lr}\text { Institute of } & \text { Food } \\
\text { Science } & \text { and } \\
\text { Technology } & \end{array}$ & $\begin{array}{l}\text { Estudo } \\
\text { experimental }\end{array}$ & $\begin{array}{l}\text { Extração de } \\
\text { compostos }\end{array}$ \\
\hline $\begin{array}{l}\text { Cavazim } \\
\& 2014\end{array}$ & Freitas, Brasil & $\begin{array}{l}\text { Relatar de forma ampla e } \\
\text { aprofundada os benefícios } \\
\text { antioxidantes do } G \text {. berry à } \\
\text { saúde humana, com ênfase na } \\
\text { acuidade visual. }\end{array}$ & Uningá Review & $\begin{array}{l}\text { Revisão } \\
\text { Bibliográfica }\end{array}$ & $\begin{array}{l}\text { Propriedade } \\
\text { s } \\
\text { Antioxidant } \\
\text { es }\end{array}$ \\
\hline $\begin{array}{l}\text { Donno } \\
\text { D. et. al, } \\
2014\end{array}$ & $\begin{array}{l}\text { Grugliasco, Itá } \\
\text { lia }\end{array}$ & $\begin{array}{l}\text { Descrever as características de } \\
\text { qualidade goji de compostos } \\
\text { potencialmente bioativos e } \\
\text { atividades antioxidante. }\end{array}$ & $\begin{array}{l}\text { Journal of funcional } \\
\text { alimentos }\end{array}$ & $\begin{array}{l}\text { Estudo } \\
\text { experimental }\end{array}$ & $\begin{array}{l}\text { Propriedade } \\
\mathrm{s} \\
\text { Antioxidant } \\
\text { es }\end{array}$ \\
\hline $\begin{array}{l}\text { Llorent- } \\
\text { Martinez } \\
\text { EJ et al, } \\
2013 \text {. }\end{array}$ & $\begin{array}{l}\text { Jaén, } \\
\text { Espanha }\end{array}$ & $\begin{array}{l}\text { Determinar o conteúdo } \\
\text { mineral presentes nas bagas de } \\
\text { goji. . }\end{array}$ & Microquímica Jornal & $\begin{array}{l}\text { Estudo } \\
\text { experimental }\end{array}$ & $\begin{array}{l}\text { Determinaçã } \\
\text { o de } \\
\text { compostos } \\
\text { minerais }\end{array}$ \\
\hline $\begin{array}{l}\text { Salgado, } \\
\text { F. } 2011\end{array}$ & $\begin{array}{l}\text { Corunha. } \\
\text { Espanha }\end{array}$ & $\begin{array}{l}\text { Demonstrar as aplicações } \\
\text { farmacológicas do G. berry e } \\
\text { suas atividades fitoterápicas. }\end{array}$ & $\begin{array}{l}\text { International Journal } \\
\text { of Acupuncture }\end{array}$ & $\begin{array}{l}\text { Estudo } \\
\text { experimental }\end{array}$ & $\begin{array}{l}\text { Atividade } \\
\text { fitoterápica }\end{array}$ \\
\hline $\begin{array}{l}\text { Forino } \\
\text { M. et. al, } \\
2015 .\end{array}$ & $\begin{array}{l}\text { Napoli, } \\
\text { Itália }\end{array}$ & $\begin{array}{l}\text { Relatar a identificação dos } \\
\text { principais compostos fenólicos } \\
\text { isolados a partir de bagas de } \\
\text { G. berry comercialmente } \\
\text { disponíveis. }\end{array}$ & Food Chemistry & $\begin{array}{l}\text { Estudo } \\
\text { experimental }\end{array}$ & $\begin{array}{l}\text { Determinaçã } \\
\text { o de } \\
\text { compostos } \\
\text { antioxidante } \\
\text {. }\end{array}$ \\
\hline $\begin{array}{l}\text { Horszwa } \\
\text { ld \& } \\
\text { Andlauer } \\
2011 .\end{array}$ & $\begin{array}{l}\text { Sion, } \\
\text { Suíça }\end{array}$ & \begin{tabular}{llrr} 
Apresentar & \multicolumn{2}{c}{ métodos para } \\
determinação & de compostos \\
bioativos e & adaptá-las à \\
medição & de & microplacas \\
moderna. & & \\
\end{tabular} & $\begin{array}{l}\text { Journal of Berry } \\
\text { Research }\end{array}$ & $\begin{array}{l}\text { Estudo } \\
\text { experimental }\end{array}$ & $\begin{array}{l}\text { Determinaçã } \\
\text { o de } \\
\text { compostos }\end{array}$ \\
\hline $\begin{array}{l}\text { Karioti } \\
\text { A. et al, } \\
2014\end{array}$ & $\begin{array}{l}\text { Firenze, } \\
\text { Itália }\end{array}$ & $\begin{array}{l}\text { Desenvolver e aperfeiçoar um } \\
\text { protocolo de extração para o } \\
\text { conteúdo de micro-ondas } \\
\text { instáveis. }\end{array}$ & $\begin{array}{l}\text { J. Agric. Chem alime } \\
\text { ntos. }\end{array}$ & $\begin{array}{l}\text { Estudo } \\
\text { experimental }\end{array}$ & $\begin{array}{l}\text { Método de } \\
\text { extração }\end{array}$ \\
\hline $\begin{array}{l}\mathrm{Li} \text { J. et } \\
\text { al, } 2014 \text {. }\end{array}$ & $\begin{array}{l}\text { Ohio, } \\
\text { Estados } \\
\text { Unidos }\end{array}$ & $\begin{array}{l}\text { Realizar o isolamento guiado } \\
\text { por bioatividade, identificação } \\
\text { e avaliação biológica de } \\
\text { compostos. }\end{array}$ & $\begin{array}{l}\text { J. Agric. Chem alime } \\
\text { ntos., }\end{array}$ & $\begin{array}{l}\text { Estudo } \\
\text { experimental }\end{array}$ & $\begin{array}{l}\text { Isolamento } \\
\text { de } \\
\text { compostos e } \\
\text { avaliação } \\
\text { biológica. }\end{array}$ \\
\hline $\begin{array}{l}\text { Magalhã } \\
\text { es, } \\
\text { Camargo } \\
\& \\
\text { Higuchi, } \\
2013\end{array}$ & $\begin{array}{ll}\text { São } & \text { Paulo, } \\
\text { Brasil } & \end{array}$ & $\begin{array}{l}\text { Descrever a ação de } \\
\text { substâncias ativas fitoterápicas } \\
\text { no tratamento da celulite, } \\
\text { procurando uma alternativa } \\
\text { não invasiva para o } \\
\text { tratamento. }\end{array}$ & $\begin{array}{l}\text { Interfac EHS Saúde, } \\
\text { Meio Ambiente e } \\
\text { Sustentabilidade }\end{array}$ & $\begin{array}{l}\text { Revisão } \\
\text { Bibliográfica }\end{array}$ & $\begin{array}{l}\text { Tratamento } \\
\text { da celulite } \\
\text { com fins } \\
\text { cosméticos }\end{array}$ \\
\hline $\begin{array}{l}\text { Martins, } \\
\text { Coimbra } \\
\& \\
\text { Schlichti } \\
\text { ng, } 2014\end{array}$ & $\begin{array}{l}\text { Maringá, } \\
\text { Brasil }\end{array}$ & $\begin{array}{l}\text { Conscientizar pacientes } \\
\text { clínicos da importância da } \\
\text { orientação do médico e do } \\
\text { farmacêutico na utilização de } \\
\text { fitoterápicos. }\end{array}$ & Uningá Review & $\begin{array}{l}\text { Revisão } \\
\text { Bibliográfica }\end{array}$ & Toxicidade \\
\hline
\end{tabular}




\begin{tabular}{|c|c|c|c|c|c|}
\hline $\begin{array}{l}\text { Mendes } \\
\text { M. et.al, } \\
2015\end{array}$ & $\begin{array}{l}\text { Porto, } \\
\text { Portugal }\end{array}$ & $\begin{array}{l}\text { Avaliar a superfície } \\
\text { resposta de } \\
\text { extração assistida por por micro- } \\
\text { ondas para L. barbarum } \\
\text { compostos bioativos. }\end{array}$ & $\begin{array}{l}\text { Innovative Food Scie } \\
\text { nce and Emer- } \\
\text { ging Technologies }\end{array}$ & $\begin{array}{l}\text { Estudo } \\
\text { experimental }\end{array}$ & $\begin{array}{l}\text { Composição } \\
\text { Química }\end{array}$ \\
\hline $\begin{array}{l}\text { Mikulic- } \\
\text { Petkovse } \\
\text { k, et. al, } \\
2012 \text {. }\end{array}$ & $\begin{array}{l}\text { Ljubljana, } \\
\text { Eslovênia. }\end{array}$ & $\begin{array}{l}\text { Analisar a composição de } \\
\text { açucares, ácidos orgânicos, e } \\
\text { fenóis totais em } 25 \text { espécies de } \\
\text { bagas silvestres ou cultivadas. }\end{array}$ & $\begin{array}{lll}\text { Journal of } & \text { Food } \\
\text { Science } & & \end{array}$ & $\begin{array}{l}\text { Estudo } \\
\text { experimental }\end{array}$ & $\begin{array}{l}\text { Determinaçã } \\
0 \quad \text { de } \\
\text { compostos }\end{array}$ \\
\hline $\begin{array}{l}\text { Muselin } \\
\text { F. et al. } \\
2015\end{array}$ & $\begin{array}{l}\text { Timisoara, Ro } \\
\text { mênia }\end{array}$ & $\begin{array}{l}\text { Avaliar benefícios da Doca } \\
\text { amarela (Rumex Crispus L.) e } \\
\text { G. berry (L. Barbarum L.) em } \\
\text { ratos com diabetes mellitus. }\end{array}$ & $\begin{array}{l}\text { Ciência Animal e Bio } \\
\text { tecnologia }\end{array}$ & $\begin{array}{l}\text { Estudo } \\
\text { experimental }\end{array}$ & $\begin{array}{l}\text { Tratamento } \\
\text { de Diabetes }\end{array}$ \\
\hline $\begin{array}{l}\text { Navarro } \\
\text { P. et. al, } \\
2011\end{array}$ & $\begin{array}{l}\text { Orihuela, } \\
\text { Espanha }\end{array}$ & $\begin{array}{l}\text { Avaliar a eficiência de tipos de } \\
\text { CDs ( } \beta \text {-CD e HP- } \beta \text {-CD) em } \\
\text { encapsular compostos } \\
\text { antioxidantes de um alimento } \\
\text { funcional, suco de tangerina } \\
\text { enriquecido com extrato de } \\
\text { romã e suco de G. berry }\end{array}$ & $\begin{array}{l}\text { Journal of } \\
\text { Food Science }\end{array}$ & $\begin{array}{l}\text { Estudo } \\
\text { experimental }\end{array}$ & $\begin{array}{l}\text { Alimento } \\
\text { funcional }\end{array}$ \\
\hline $\begin{array}{l}\text { Potterat, } \\
2009\end{array}$ & Basileia, Suíça & $\begin{array}{l}\text { Relatar a química, } \\
\text { farmacologia e segurança da } \\
\text { planta, no uso de produtos do } \\
\text { Goji no mercado de novos } \\
\text { alimentos. }\end{array}$ & Planta Médica & $\begin{array}{l}\text { Estudo } \\
\text { experimental }\end{array}$ & $\begin{array}{l}\text { Atividade } \\
\text { farmacológi } \\
\text { cas }\end{array}$ \\
\hline $\begin{array}{l}\text { Zhang Q } \\
\text { et. al, } \\
2016\end{array}$ & $\begin{array}{l}\text { Chongqing, } \\
\text { China }\end{array}$ & $\begin{array}{l}\text { Determinar o } r r \text { conteúdo } \\
\text { composição da } \text { CFs principais } \\
\text { (incluindo } \\
\text { carotenoides, polifenóis, } \\
\text { genótipos de goji nativos } \\
\text { chineses e avaliar a sua } \\
\text { atividade antioxidante). }\end{array}$ & Food Chemistry. & $\begin{array}{l}\text { Estudo } \\
\text { experimental }\end{array}$ & $\begin{array}{l}\text { Constituinte } \\
\mathrm{s} \\
\text { funcionais e } \\
\text { ati- } \\
\text { vidades anti- } \\
\text { oxidantes }\end{array}$ \\
\hline $\begin{array}{l}\text { Redgwel } \\
1 \text { et al, } \\
2011\end{array}$ & $\begin{array}{l}\text { Konolfingen, } \\
\text { Suíça }\end{array}$ & $\begin{array}{l}\text { Relatar a investigação mais } \\
\text { detalhada das frações de Wolf } \\
\text { Berry isoladas e purificações } \\
\text { por precipitação. }\end{array}$ & $\begin{array}{l}\text { Carbohydrate and } \\
\text { Polymers }\end{array}$ & $\begin{array}{l}\text { Estudo } \\
\text { experimental }\end{array}$ & $\begin{array}{l}\text { Isolamento } \\
\text { de } \\
\text { compostos }\end{array}$ \\
\hline $\begin{array}{l}\text { Reeve E. } \\
\text { et al, } \\
2010\end{array}$ & $\begin{array}{l}\text { Sydney, } \\
\text { Austrália }\end{array}$ & $\begin{array}{l}\text { Examinar o efeito } \\
\text { suco de Goji por via oral na } \\
\text { inflamação induzida por radiaç } \\
\text { ão UV. }\end{array}$ & $\begin{array}{l}\text { Photochem. Photobio } \\
\text { 1. Science }\end{array}$ & $\begin{array}{l}\text { Estudo } \\
\text { experimental }\end{array}$ & $\begin{array}{l}\text { Atividade } \\
\text { farmacológi } \\
\text { cas }\end{array}$ \\
\hline $\begin{array}{l}\text { Rivera et } \\
\text {. al, } \\
2012\end{array}$ & $\begin{array}{l}\text { Chicago, } \\
\text { Estados } \\
\text { Unidos }\end{array}$ & $\begin{array}{l}\text { Relatar a provável interação } \\
\text { entre a } L \text {. barbarum (Goji) e } \\
\text { Varfarina. }\end{array}$ & Farmacoterapia & $\begin{array}{l}\text { Estudo } \\
\text { experimental }\end{array}$ & $\begin{array}{l}\text { Interação } \\
\text { medicament } \\
\text { osa }\end{array}$ \\
\hline $\begin{array}{l}\text { Redgwel } \\
\text { l } \\
\text { RJ. et al, } \\
2011 .\end{array}$ & $\begin{array}{l}\text { Konolfingen, } \\
\text { Suíça }\end{array}$ & $\begin{array}{l}\text { Analisar o polissacarídeo total } \\
\text { (solúvel e insolúvel contido) e } \\
\text { identificar o r principal } \\
\text { polissacarídeo de }\end{array}$ & $\begin{array}{l}\text { Carbohydrate and } \\
\text { Polymers }\end{array}$ & $\begin{array}{l}\text { Estudo } \\
\text { experimental }\end{array}$ & $\begin{array}{l}\text { Isolamento e } \\
\text { determinaçã } \\
\text { o de } \\
\text { compostos }\end{array}$ \\
\hline $\begin{array}{l}\text { Rotar } \\
\mathrm{Am} \text { et } \\
\mathrm{al}, 2015\end{array}$ & $\begin{array}{l}\text { Cluj-apoca, } \\
\text { Romênia }\end{array}$ & $\begin{array}{l}\text { Investigar as bagas goji com o } \\
\text { mel, na qualidade sensorial, as } \\
\text { propriedades químicas, de } \\
\text { bactérias de ácido láctico e } \\
\text { microflora concomitante no } \\
\text { iogurte. }\end{array}$ & $\begin{array}{l}\text { Not Bot } \text { Horti } \\
\text { Agrobo }\end{array}$ & $\begin{array}{l}\text { Estudo } \\
\text { experimental }\end{array}$ & $\begin{array}{l}\text { Alimento } \\
\text { funcional }\end{array}$ \\
\hline $\begin{array}{l}\text { Silva \& } \\
\text { Degáspa } \\
\text { ri, } 2014\end{array}$ & $\begin{array}{l}\text { Curitiba, } \\
\text { Brasil }\end{array}$ & $\begin{array}{l}\text { Analisar alguns artigos } \\
\text { científicos que abordam as } \\
\text { propriedades nutricionais e } \\
\text { efeitos adversos da "G. berry". }\end{array}$ & Visão Acadêmica & $\begin{array}{l}\text { Revisão } \\
\text { Bibliográfica }\end{array}$ & $\begin{array}{l}\text { Alimento } \\
\text { funcional }\end{array}$ \\
\hline Tingting & New York, & Indicar a espectroscopia de & Anal alimentos. Méto & Estudo & Determinaçã \\
\hline
\end{tabular}




\begin{tabular}{|c|c|c|c|c|c|}
\hline $\begin{array}{l}\text { et. al, } \\
2015 \text {. }\end{array}$ & $\begin{array}{l}\text { Estados } \\
\text { Unudos }\end{array}$ & $\begin{array}{l}\text { NIR combinado com LS-SVM } \\
\text { e Si-PLS para avaliar a } \\
\text { qualidade de G. Berry. }\end{array}$ & dos & experimental & $\begin{array}{l}\text { o de } \\
\text { compostos. }\end{array}$ \\
\hline $\begin{array}{l}\text { Wenjun } \\
\text { H. et. al, } \\
2015\end{array}$ & $\begin{array}{l}\text { Beijing, } \\
\text { China }\end{array}$ & $\begin{array}{l}\text { Avaliar a qualidade } \text { de } \\
\text { crescimento e de frutos do } \\
\text { tomateiro e do } \text { e. berry } \\
\text { enxertado. }\end{array}$ & $\begin{array}{l}\text { Scientia } \\
\text { Horticulturae }\end{array}$ & $\begin{array}{l}\text { Estudo } \\
\text { experimental. }\end{array}$ & $\begin{array}{l}\text { Controle de } \\
\text { qualidade } \\
\text { do tomateiro } \\
\text { e Goji } \\
\text { enxertados. }\end{array}$ \\
\hline $\begin{array}{l}\text { Zhang } \\
\text { Z. et al, } \\
2010\end{array}$ & $\begin{array}{l}\text { Yinchuan, } \\
\text { China }\end{array}$ & $\begin{array}{l}\text { Compreender os mecanismos } \\
\text { de atividades farmacológicas } \\
\text { dos frutos Goji silvestres com } \\
\text { propriedades } \\
\text { antienvelhecimento } \\
\text { antitumorais na medicina } \\
\text { tradicional. }\end{array}$ & $\begin{array}{l}\text { Archives } \\
\text { of Pharmatical } \\
\text { Research. }\end{array}$ & $\begin{array}{l}\text { Estudo } \\
\text { experimental }\end{array}$ & $\begin{array}{l}\text { Atividades } \\
\text { farmacológi } \\
\text { cas }\end{array}$ \\
\hline $\begin{array}{l}\text { Züleyha } \\
\text { Endes et. } \\
\text { al, } 2014\end{array}$ & $\begin{array}{l}\text { Konya, } \\
\text { Turquia }\end{array}$ & $\begin{array}{l}\text { Analisar } \\
\text { propriedades físico- } \\
\text { químicas, ácido graxos, metais } \\
\text { pesados } \\
\text { e minerais no goji (L. barbaru } \\
\text { m.). }\end{array}$ & $\begin{array}{l}\text { J.Proc. } \\
\text { Agroa eTecnol. }\end{array}$ & $\begin{array}{l}\text { Estudo } \\
\text { experimental }\end{array}$ & $\begin{array}{l}\text { Propriedade } \\
\text { s Físico- } \\
\text { Quimicas }\end{array}$ \\
\hline
\end{tabular}

Gráfico 1 - Principais aplicações dos estudos realizado com o G. berry.

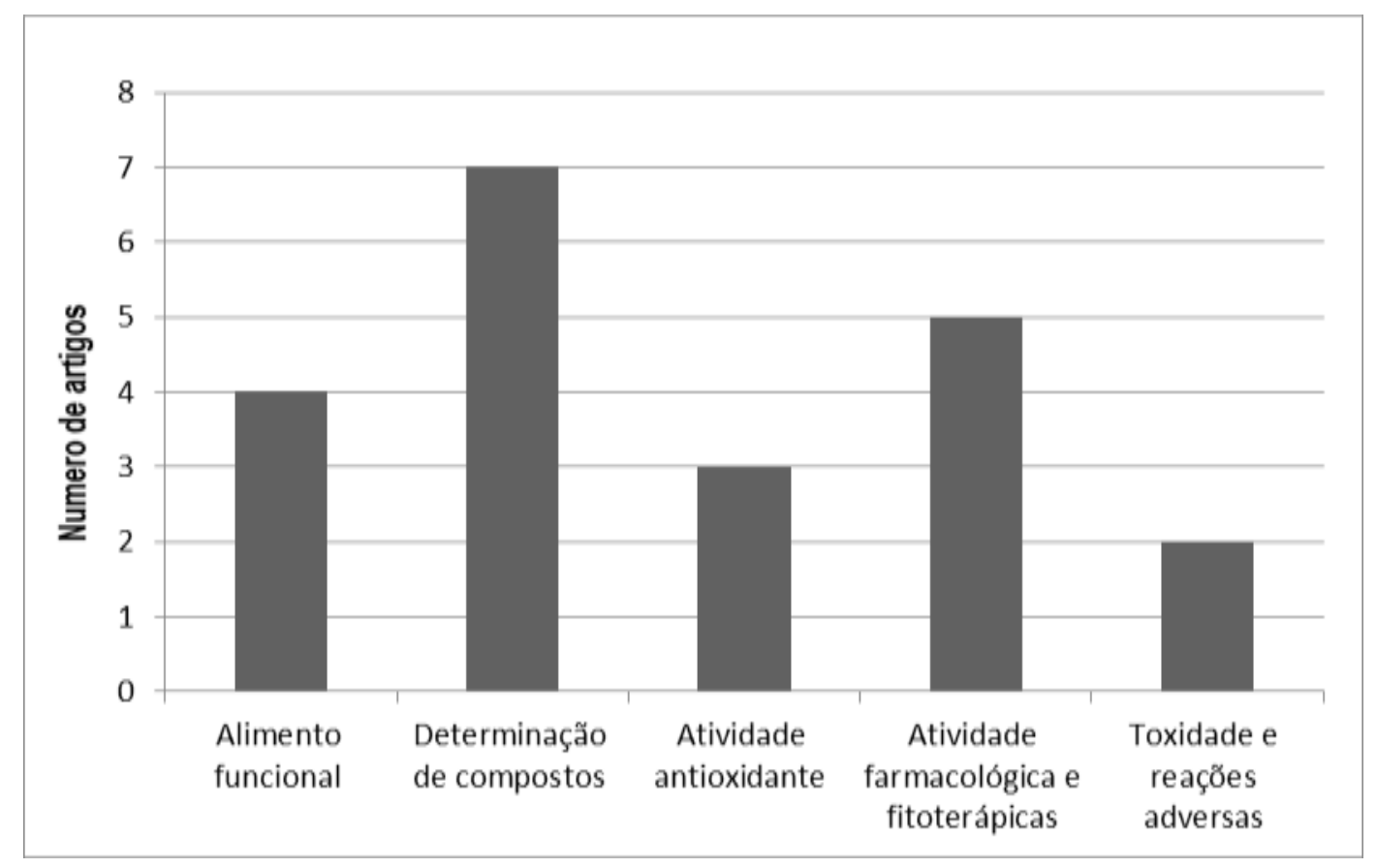


Gráfico 2 - Periodicidade das publicações sobre o uso do G. berry.

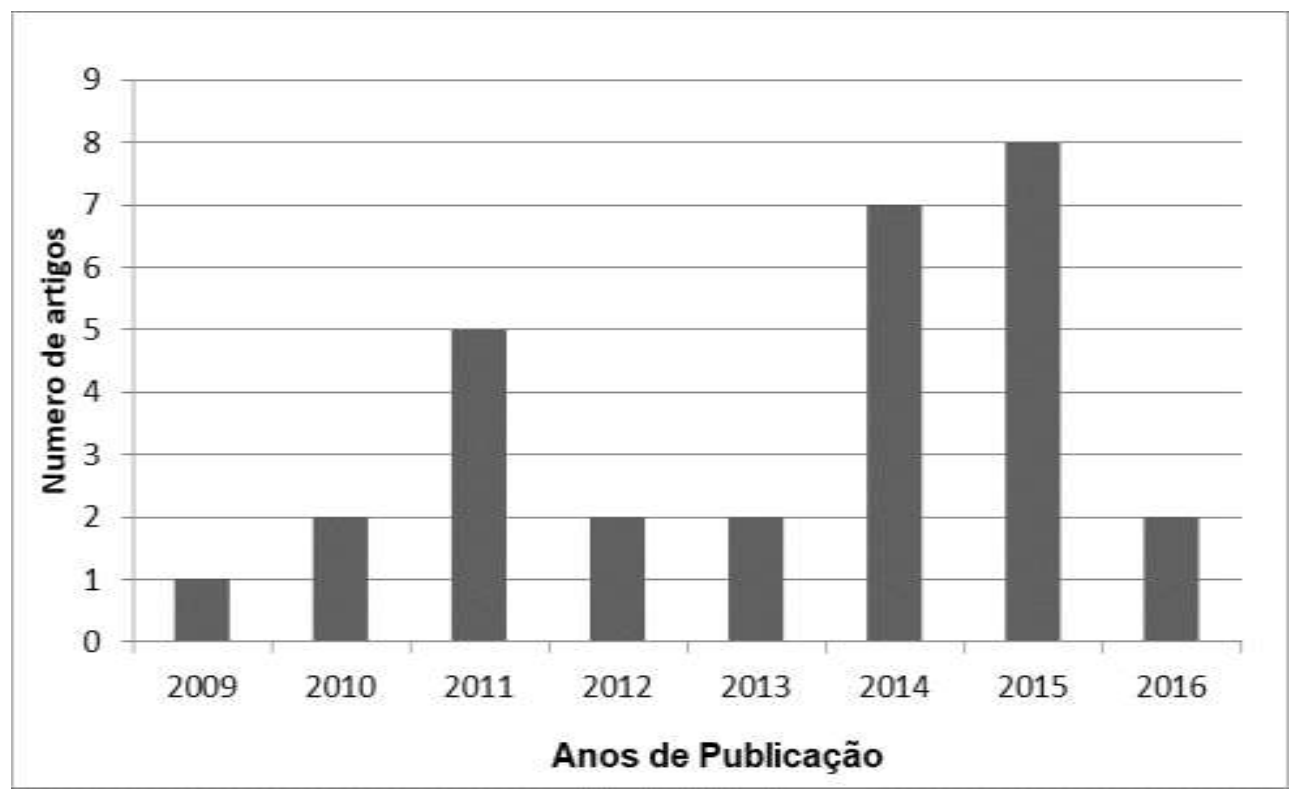

As propriedades probióticas e a viabilidade das bactérias de ácido láctico de produtos lácteos fermentados podem ser melhoradas por adição de compostos bioativos das bagas do G. berry. Forma desenvolvidos dois tipos de iogurtes: iogurte e as bagas e iogurte com mel e bagas. A adição de mel afetou toda a microflora iogurte, manifestando efeito bactericida. A adição de bagas de $G$. berry mantém a viabilidade em níveis probióticos $\left(10^{6}\right.$ $\left.10^{7} \log \quad \mathrm{UFC} / \mathrm{ml}\right)$ durante 21 dias de armazenamento em comparação com iogurte clássico (ROTAR et al, 2015).

O suco de G. berry, oferecem proteção significativa contra os raios UV, estresse oxidativo, fatores reconhecidos como prérequisito para contribuições fotocarcinogênese, portanto o suco pode vir a ser um complemento útil às estratégias de fotoprotetores tópicos, na prevenção de câncer de pele (POTTERAT, 2010).
O uso de medicamentos que são administrados simultaneamente a um paciente, eles poderão interagir entre si causando uma diminuição ou aumento do efeito terapêutico um do outro (HOEFLER, 2010). Estudos mostram que além dos benefícios já relatados, as bagas do G. berry possui interação medicamentosa quando utilizada ao mesmo tempo que à varfarina, sua indicação por profissionais devem restringir a associação com este anticoagulante (CAVAZIN e FREITAS, 2014).

Além da interação entre o $G$. berry e a varfarina, existem relatos na literatura de pacientes que desenvolveram sintomas alérgicos e até reação anafilática depois do consumo das bagas, apresentando sinais e sintomas como urticária, edema, rinite aguda e dispneia (BALLARIN et al., 2013).

Foi relatada uma reação de fotossensibilidade em um paciente que utilizava bagas de G. berry, produzindo um aparecimento de erupções pruriginosas nas áreas expostas ao 
sol, com o uso deste produto descobriram que o paciente tinha diminuição da radiação ultravioleta (MED-UVB) (BERNAL et al, 2011).

Pesquisas vêm sendo realizadas, sobre a ação medicamentosa e a sua utilização do $G$. berry como alimento funcional. A avaliação bioquímica de pequenos recursos genéticos de frutas, identificação de compostos fenólicos totais e suas propriedades como agentes naturais são de extrema significância (MIKULICPETKOVSEK et al., 2012).

Aliado ao interesse de alimentos com alto valor nutracêutico, o estudo na composição da fruta $G$. berry, tem se intensificado cada vez mais por causa de uma maior consciência de seus possíveis efeitos benéficos para a saúde, pois são ricas fontes de micronutrientes e compostos orgânicos, tais como: ácidos orgânicos, açúcares e compostos fenólicos (MENDES et al., 2016).

Os compostos orgânicos, que atuam como antioxidantes, dados recentes mostram que elas ajudam a otimizar a saúde humana ao neutralizar os radicais livres no corpo (ENDES et al., 2015). No entanto, precisa-se realizar mais estudos sobre a composição química das bagas do $G$. berry e seu mecanismo de ação (CARVALHO et al., 2016).

As bagas do $G$. berry, podem ser comercializadas principalmente secas, mas também são comercializadas na forma de sucos, óleos, extratos, compotas, marmeladas, geleias e barra de cereal. São atribuídas as bagas numerosas propriedades nutricionais, porém poucas foram comprovadas cientificamente (BALCELLS; DE KAIRÚZ; NADER-MACIAS, 2013).
Forino et al., (2016), isolou e identificou os compostos fenólicos: ácido caféico, ácido pcumárico, rutina, escopoletina, N-tiramina transferuloil, e N-tiramina-cis-feruloil, e a N-tiraminaferuloil. Caracterizado como o mais abundante composto isolados a partir das bagas do G. berry, sendo que as propriedades biológicas das bagas são atribuídas principalmente ao alto teor destes compostos.

\section{CONCLUSÃO}

Os estudos mostram que nos últimos anos houve uma grande relevância em pesquisas sobre o uso das bagas do Goji Berry como fitoterápico e alimento funcional. Sendo os polissacarídeos e os compostos fenólicos, os responsáveis por várias propriedades terapêuticas, como por exemplo o seu alto poder antioxidante.

\section{REFERÊNCIAS}

ADILETTA G; Alam M. R; Cinquant I; Russo P; Albanese D; Matteo M.D. Effect of Abrasive Pretreatment on Hot Dried Goji Berry. Chem. Eng. Trans. v. 44, p.127-32, 2015.

AMAGASE H; Farnsworth N. R. A review of botanical characteristics, phytochemistry, clinical relevance in efficacy and safety of Lycium barbarum fruit (goji). Food Res. Int. v. 44, n.7, p.1702 -1717, 2011.

APPOLONI M.C. Estudo dos Compostos Bioativos da LYCIUM BARBARUM. Campo Mourão: [trabalho de conclusão de curso - Universidade Tecnológica Federal do Paraná], 2015. BALCELLS, M. F; De Kairúz, M. N; Nader-Macias, M. E. F. Composición química, valoración nutricional, satisfacción y aceptabilidad de bayas de goji (Lycium barbarum L.) y productos elaborados. Actualización en nutrición. v.14, n.4, p.275-286, 2013.

BERNAL, S. G; Pazos, L. R; Martínez, F. J. G; Ginarte, M; Granados, M. T. R; Toribio, J. Systemic 
photosensitivity due to Goji berries. Photodermatol. Photoimmunol. Photomed. v. 27, p.245-247, 2011

CARDOZO, L; Mafra, D. Alimentação Pode Levar a Benefícios para o Sistema Cardiovascular: Fato ou Ficção? Inter. J. Cardiovasc. Sci. v. 28, n.2, p. 8788,2015

CARVALHO, A. P; Mendes, M; Moreira, M. M; Cruz, D; Magalhães, J. M.; Barroso, M.F, et al. Microwave assisted extraction in wolfberries: effect on composition and bioactivity evaluated by conventional and nonconventional methodologies.

Inst. Food Sci. Tech. v. 51, n. 6, p.1401-1408, 2016.

CAVAZIM, P. F.; Freitas. G. As propriedades antioxidativas do goji berry no auxilio à melhora do centro de acuidade visual, com abordagem em tratamento da retinopatia diabética. Uningá Rev; v. 20, n.2, p.55-60, 2014.

DONNO, D.; Beccaro, G. L.; Mellano, M. G.; Cerutti, A.K.; Bounous, G. Goji berry fruit (Lycium spp.): antioxidant compound fingerprint and bioactivity evaluation. J Funct Foods. v.18, p.1070-1085, 2014.

ENDES, Z.; Uslu, N.; Özcan, M. M.; Er, F. Physicochemical properties, fatty acid composition and mineral contents of goji berry (Lycium barbarum L.) fruit. J Agroaliment. Processes Technol. v.21, n. 1, p. 36- 40, 2015.

FORINO, M; Tartaglione, L; Aversano, C. P.; Ciminiello, P. NMR-based identification of the phenolic profile os fruits of Lycium barbarum (goji berries). Isolation and structural determination of a novel N-feruloyl tyramine dimer as the most abundant antioxidant polyphenol of goji berrie. Food Chem. v.194, p.1254-1259, 2016.

HOEFLER, R. Interações Medicamentosas. Secretaria de Ciência, Tecnologia e Insumos Estratégicos. Mato Grosso do Sul, 2010.

HORSZWALD, A.; Andlauer, W. Characterisation of bioactive compounds in berry juices by traditional photometric and modern microplate methods.

J. Berry Res. v.1, n.1, p.189-199, 2011.

KARIOTI, A.; Bergonzi, M. C.; Vincieri, F.F.; Bilia, A.R. Validated Method for the Analysis of Goji Berry, a Rich Source of Zeaxanthin Dipalmitate.

J. Agric. Chem Food. v.62, p.12529 -12535, 2014.

MARTINS, G. S. G.; Coimbra, C. C. B. E.;

Schilichting, C. L. R. Toxicidade do Goji Berry

(Lyncium barbarum). Uningá Rev. v.20, n.1, p.87 -

91, 2014.
MENDES, M.; Carvalho, A. P.; Magalhães, J. M.; Moreira, M.; Guido, L.; Gomes, A. M.; Matos, C. D. Response surface ecalution of microwave extraction conditions for Lyncium barbarum bioactive compounds. Innov. Food Sci. Emerg. Technol. v. 22, p.319-326, 2016.

MIKULIC-PETKOVSEK, M.; Schmitzer, V.; Slatnar, A.; Stampar, F.; Veberic, R. HPLC-MS identification and quantification of flavanol glycosides in 28 wild and cultivated berry species. J. Food Sci. v. 135, p. $2138-2146,2012$.

MIKULIC-PETKOVSEK, M.; Schmitzer, V.; Slatnar, A.; Stampar, F.; Veberic, R. Composition of Sugars, Organic Acids, and Total Phenolics in 25 Wild or Cultivated Berry Species. J. Food Sci. v. 77, n. 10, p. 1-6, 2012.

MUSELIN, F.; Brezovan, D.; Savici, J.; Cristina, R. T.; Dumitrescu, E.; Doma, A. O. The Use of Yellow Dock (Rumex crispus L.) and Goji Berry (Lycium barbarum L.) in Alloxan Induced Diabetes Mellitus in Rats. J. Anim. Sci. Biotechnol. v.48, n.1, p.373-76, 2015.

NAVARRO, P.; Nicolas, T.C.; Gabaldon, J. A.; Mercader-Ros, M. T.; Calín-Sánchez, A.; CarbonellBarrachina A. et al. Effects of Cyclodextrin Type on Vitamin C, Antioxidant Activity, and Sensory Attributes of a Mandarin Juice Enriched with Pomegranate and Goji Berries. J. Food Sci. v. 76, n. 5, p. 319-24, 2011.

POTTERAT, O. Goji (Lycium barbarum and L. chinense): Phytochemistry, Pharmacology and Safety in the Perspective of Traditional Uses and Recent Popularity. Planta Med. v.76, p. 7-19, 2010.

REDGWELL, R. J.; Curti, D.; Wang, J.;

Dobruchowska, J. M.; Gerwig, G. J.; Kamerling, J. P.; Bucheli, P. Cell wall polysaccarides of Chinese Wolfberry (Lyncium barbarum): Part 1. Characterisation of soluble and insoluble polymer fractions. Carbohydr. Polym. v.84, n.1, p.1344-1349, 2011.

REDGWELL, R. J.; Curti, D.; Wang, J.; Dobruchowska, J. M.; Gerwig, G. J.; Kamerling, J. P.; Bucheli, P. Cell wall polysaccarides of Chinese Wolfberry (Lyncium barbarum): Part 2.

Characterisation of arabinogalactan - proteins.

Carbohydr. Polym. v. 84, n. 1, p.1075-83, 2011.

REEVE, V.E.; Allanson, M.; Arun, S. J.; Domanski, D.; Painter, N. Mice drinking goji berry juice (Lycium barbarum) are protected from UV radiation-induced skin damage via antioxidant pathways.

Photochem. Photobiol. Sci. v.9, p.601- 607, 2011. 
RIVERA, C. A.; Ferro, C. L.; Bursua, A. J.; Pharm, D.; Gerber, B. S. Probable Interaction Between Lycium barbarum (Goji) and Warfarin. Case Report. v. 32, n. 3, p. 50-53, 2012.

ROTAR, A. M.; Vodnar, D. C.; Bunghez, F.;

Cătunescu, G. M.; Pop, C. R.; Jimborean, M, et al. Effect of Goji Berries and Honey on Lactic Acid Bacteria Viability and Shelf Life Stability of Yoghurt. Not Bot Horti Agrobo. v.43, n. 1, p. 197-203, 2015.

SALGADO, F. La realidad sobre el "Gou Qi Zi” o bayas Goji (Fructus Lycii). Inter.I J. Acupuncture, Corunha. v.5, n.1, p. 82-86, 2011.

SILVA, J. C. F.; Desgápari, C. H. Propriedades nutricionais e efeitos adversos da "Goji Berry" ( Lycium barbarum L.), Visão Acadêmica. v.15, n.3, p. 67- 80, 2014.

TINGTING, S.; Xiaobo, Z.; Jiyong, S.; Zhihua, L.; Xiaowei, H.; Yiwei, X.; Wu, C. Determination Geographical Origin and Flavonoids Content of Goji Berry Using Near-Infrared Spectroscopy and Chemometrics. Food Anal. Meth. v.9, p. 68-79, 2016.

ZHANG, Q.; Chen, W.; Zhao, J.; Xi, W. Functional ingredients and antioxidant activities of eight Chinese native goj genotypes. Food Chem. v. 200, p. 230236,2016

ZHANG, Z.; Liu, X.; Zhang, X.; Liu, J.; Hao, J.; Yang, X.; Yujiong, W. Functional constituents and antioxidant activites of eight Chinese native goji genotypes. Arch. Pharm. Res. v. 34, n. 5, p.801-810, 2011

\author{
Valdiléia Teixeira Uchôa \\ Doutora em Ciências - UFAL. \\ Mestre em Química e Biotecnologia -UFAL. \\ Professora adjunto da Universidade Estadual do \\ Piauí.
}

Wesley Barros da Silva Passos
Licenciado em Química - UESPI 